\title{
"Acabou comigo como pessoa" A caracterização da violência doméstica a partir da percepção de mulheres violentadas
}

\author{
Vanessa Machado Martins \\ Carolina Bunn Bartilotti
}

“Acabou comigo como pessoa": A caracterização da violência doméstica a partir da
percepção de mulheres violentadas Resumo: A presente pesquisa trata da caracterização da violência doméstica a partir da percepção de mulheres violentadas. Para tanto foi desenvolvido um estudo descritivo com quatro mulheres vítimas de violência doméstica da região da grande Florianópolis. Foi possível constatar que o tipo de violência mais citado foi a violência física. As mulheres atribuem o uso de drogas, ciúme, separação e a cultura familiar do agressor como as principais causas da ocorrência de violência doméstica. As consequências físicas mais citadas foram problemas de saúde, fraturas e marcas no corpo; as sociais foram afastamento da família, de amigos e trabalho, julgamento social e vergonha. Entre os danos psicológicos apareceram a mágoa, raiva, medo, rebaixamento de humor, baixa autoestima, intolerância/impaciência, perda de libido. As estratégias de enfrentamento para diminuição da situação de violência foram pedir auxílio a outrem, defesa, diminuição de convivência com o agressor, separação, ficar quieta e religiosidade.

Palavras-chave: Violência doméstica. Consequências da violência doméstica. Relações de gênero.

"Finished with me as a person": The characterization of domestic violence from the perception of raped women

Abstract: The presenter search deals with the characterization of domestic violence from the perception of battered women. However, a descriptive study with four female victims of domestic violence in the greater Florianopolis was developed. It was found that the most cited type of violence was physical violence. Women attribute the use of drugs, jealousy, separation and family culture of the aggressor as the main causes of the occurrence of domestic violence. The most common physical consequences were health problems, fractures and marks on the body; social were separation from family, friends and work, social judgment and shame. Among the psychological damage, appear hurt, anger, fear, lowering mood, low self-esteem, intolerance / impatience, loss of libido. The strategies to decrease violence situation was asking help to others, defense, lower living with the abuser, separation, be quiet and religiosity.

Keywords: Domestic violence. Consequences of domestic violence. Gender relations. 


\section{Introdução}

A violência doméstica é uma violência de gênero, independente de qual seja o tipo - física, psicológica, moral, sexual ou patrimonial. Gênero é um conceito das Ciências Sociais para diferenciar o que é ser mulher e ser homem, esses papéis são ensinados socialmente como condição de ser homem e de ser mulher, uma maneira ideal do masculino e feminino (GOMES et al, 2007). É uma construção social feita a partir das características biológicas, conforme afirmam Fonseca e Lucas (2006). A construção social se dá pela percepção de qual sexo pertence, a partir de fatores biológicos. "Neste processo, o sexo e os aspectos biológicos ganham significados sociais decorrentes das possibilidades fisicas e sociais de homens e mulheres, delimitando suas caracteristicas e espaços onde podem atuar" (FONSECA - LUCAS, 2006, p.4-5)

Gomes et al (2007) complementam quando dizem que os papéis de gênero foram passados de geração em geração, como condição de ser homem ou mulher, é intergeracional. As mulheres devem ser delicadas, sensíveis, passivas, subordinadas e obedientes devido a condição biológica de engravidar e amamentar, cuidar dos filhos, do marido e do lar. Os homens são relacionados ao espaço público, provedores e chefe da casa, viris, corajosos e agressivos. Dessa forma os papéis de homem e mulher são construídos a partir do que a sociedade ensina, espera e determina. Ao menino é ensinado que deve ser como o pai quando se tornar um homem: ser forte, insensível e não externalizar os sentimentos. A menina deve ser como a mãe e possuir as características de ser "doce, dependente e insegura" (FONSECA e LUCAS, 2006, p. 4).

Strey (1998) refere que o gênero possui uma hierarquia de poder que é associada ao homem, com isso ressalta a questão do patriarcado que "é uma forma de hierarquia, em que os homens detêm o poder e as mulheres são subordinadas" (p. 185). Gomes et al (2007) ressaltam que há uma "cultura patriarcal" refletida nas famílias que estimulam os papéis de homem e mulher. O patriarcado é o poder dado aos homens, sendo que as mulheres são subordinadas à eles, assim "legitima o controle da sexualidade, dos corpos e da autonomia femininas; e estabelece papéis sexuais e sociais nos quais o masculino tem vantagens" (NARVAZ e KOLLER, 2006, p.50). Nas famílias, geralmente, os homens são extremamente valorizados, por possuir o poder, a autonomia e a dominação em relação à mulher. Ao homem é destinado o poder e à mulher a subordinação, que deve obediência a esse homem (STREY, 1998). Neste sentido, Siqueira (2002) aponta que ambos não possuem os mesmos direitos, a relação de gênero é assimétrica: o homem possui o poder e a mulher não.

A hierarquia social de submissão e poder contribui e muito para que ocorra a violência doméstica. Segundo Gomes et al (2007) a violência doméstica é historicamente comum em todas as classes sociais, porém só começou a ter visibilidade como problema social e de saúde pública no final da década de 60 do séc. XX. A partir dessa época a temática tem se tornado uma categoria política de reivindicação feminista, exigindo respostas políticas para a problemática; com isso as mulheres passam a questionar os papéis que lhe são atribuídos. Essa reivindicação feminista "tornou visível a violência, qualificando-a como uma violação dos direitos humanos e como um comportamento criminal, devendo ser encarada justamente desta maneira pelos profissionais [da saúde, segurança e justiça] que lidam com essas vítimas" (GARBIN et al, 2006, p.2568). 
Em 1940, o Código Penal Brasileiro caracterizou a agressão física do marido contra a mulher como delito sujeito a punição, embora não tenha incluído o crime de estupro do marido contra à mulher (ADEODATO et al, 2005). Somente sessenta e seis anos depois foi criada uma lei específica para legislar sobre a violência contra a mulher, a Lei 11.340, conhecida como a Lei Maria da Penha.

Maria da Penha, nascida em 1945 é cearense e farmacêutica bioquímica que durante vários anos sofreu violência doméstica. A última situação ocorreu em 1983 enquanto dormia: seu marido Marco Antonio Heredia Viveros, a deixou paraplégica com um tiro nas costas. Ele foi julgado duas vezes e condenado, mas saiu em liberdade por recursos dos advogados de defesa. Em 1994 Maria da Penha publicou o livro: "Sobrevivi... Posso contar", reeditado em novembro de 2010, que serviu para denunciar o Brasil na Comissão Interamericana de Direitos Humanos da Organização dos Estados Americanos. Com essa denúncia o Brasil foi condenado internacionalmente, pela maneira como eram tratados os casos de violência contra a mulher no país e teve que cumprir recomendações como a de "mudar a legislação brasileira que permitisse, nas relações de gênero, a prevenção e a proteção da mulher em situação de violência doméstica e a punição do agressor" (INSTITUTO MARIA DA PENHA, 2012). Com isso criou-se um projeto de lei que, após aprovado na Câmara e no Senado Federal, foi transformado na Lei Federal 11.340; essa lei foi promulgada em 07 de agosto de 2006 (BRASIL, 2006).

Conforme o art. $5^{\circ}$ da Lei 11.340, "se configura violência doméstica e familiar contra a mulher qualquer ação ou omissão baseada no gênero que lhe cause morte, lesão, sofrimento físico, sexual ou psicológico e dano moral ou patrimonial" (BRASIL, 2006). A Lei 11.340 tem como objetivo de "coibir, prevenir, punir e erradicar a violência doméstica e familiar contra a mulher", assim criando mecanismos de "assistência e proteção às mulheres que sofrem essa violência". Segundo a lei a violência contra a mulher pode acontecer no "âmbito da unidade doméstica, no âmbito da família e em qualquer relação íntima de afeto" (BRASIL, 2006).

A violência doméstica e familiar contra a mulher apresenta diferentes formas:

\begin{abstract}
A violência física, entendida como qualquer conduta que ofenda sua integridade ou saúde corporal. A violência psicológica, entendida como qualquer conduta que lhe cause dano emocional, diminuição da auto-estima ou qualquer outro meio que lhe cause prejuízo à saúde psicológica e à autodeterminação. A violência sexual, entendida como qualquer conduta que a constranja a presenciar, a manter ou a participar de relação sexual não desejada. A violência patrimonial, entendida como qualquer conduta que configure retenção, subtração, destruição parcial ou total de seus objetos, instrumentos de trabalho, documentos pessoais, bens, incluindo os destinados a satisfazer suas necessidades. A violência moral, entendida como qualquer conduta que configure calúnia, difamação ou injúria (BRASIL, 2006).
\end{abstract}

Conforme registros da Central de Atendimento à Mulher (Ligue 180), de abril de 2006 a março de 2012 foram recebidas 2.527.493 ligações com várias solicitações. Os relatos de violência, juntamente com as denúncias de tráfico, contabilizaram 306.576 ligações. Em 2012, de janeiro a março foram registradas 
201.569 chamadas com solicitações variadas, dessas chamadas, 24.775 foram ligações referentes às denúncias de violência contra mulher no âmbito mais geral (e não apenas de violência doméstica), registrou-se: 14.296 casos de violência física; 6.482 casos de violência psicológica; 2.973 casos de violência moral; 504 casos de violência sexual e 425 casos de violência patrimonial. $92,3 \%$ se tratavam de violência doméstica e familiar, sendo que 80,3\% das denunciantes foram as próprias vítimas (BRASIL, 2012).

$\mathrm{Na}$ pesquisa realizada por Garbin et al (2006) foi possível perceber que na maioria dos casos de violência doméstica os agressores são os próprios maridos. Da mesma forma, na pesquisa realizada pela Central de Atendimento à Mulher sobre violência contra mulher, nota-se que $98,9 \%$ dos casos de violência contra a mulher, os agressores são homens que tiveram algum vínculo afetivo, caracterizando como casos de violência doméstica (BRASIL, 2012). Com isso o agressor (em geral o companheiro), representa o "manipulador perverso consumindo por inteiro, dando ordens, intimidando, desvalorizando, diminuindo a auto-estima e humilhando-as" (LABRONICI, 2012, p. 628). As mulheres vítimas de violência doméstica acabam sendo fantoches nas mãos desses agressores. Somente quando ocorre uma ameaça de morte é que elas, de certa forma, percebem todo o ciclo de violência pelo qual passam a recorrer ao apoio dos profissionais envolvidos nos projetos de políticas públicas que promovem assistência a elas (LABRONICI, 2012).

No início a violência é "lenta e silenciosa", o agressor "não lança mão de agressões físicas, mas parte para o cerceamento da liberdade individual da vítima, avançando para o constrangimento e humilhação" (GALVÃO e ANDRADE, 2004, p. 99). Antes de o agressor começar a violentar fisicamente, ele precisa que a vítima esteja com baixa auto-estima, se sinta humilhada, ridicularizada, deixando-a isolada, para posteriormente agredi-la fisicamente (GALVÃO e ANDRADE, 2004).

Muitos podem ser os fatores que causam a violência doméstica. Day et al (2003) elencam um conjunto de aspectos que levam à essa violência, "fatores pessoais, situacionais e socioculturais" (p. 15). Fonseca e Lucas (2006) salientam algumas causas da violência doméstica, referindo a educação diferenciada entre homens e mulheres, como definidora da manutenção de uma cultura patriarcal, como também "o álcool, as drogas, cansaço e estresse, dependência emocional, ciúmes e vigilância excessiva que podem desencadear o descontrole emocional e os atos agressivos" (p. 7-8).

Labronici (2012) afirma que as mulheres vítimas de violência permanecem no silêncio por muito tempo, sem enfrentar ou ao menos sair da situação de risco. Muitas vezes conseguem se mobilizar em relação à violência que sofrem somente quando ocorre uma ameaça à vida, quando "são surpreendidas por um comportamento de violência extrema, no qual o agressor, concretamente, tenta matá-las, agredir e/ou matar os filhos" (LABRONICI, 2012, p. 629). Com o desejo de romper com o silêncio, essas mulheres recorrem a grupos de apoio social, buscando enfrentar de alguma forma a situação vivenciada. Nesses grupos de apoio às mulheres vítimas de violência é possível falar "sobre o trauma vivido" e assim significar de outra forma essa situação de sofrimento, estimulando o processo de resiliência (LABRONICI, 2012).

Galvão e Andrade (2004) referem um aspecto interessante da violência doméstica: a desistência das mulheres em denunciar os agressores ou não darem continuidade nos processos. Eles afirmam que isso acontece devido às promessas que os agressores fazem que irão mudar, de que a agressão foi uma situação isolada e de que 
não voltará a acontecer; os agressores fazem com que as mulheres vítimas acreditem numa possibilidade de reconciliação. Garbin et al (2006) apontam que o aspecto que mais influencia para a não denúncia e permanência da mulher com o agressor é a condição financeira e isso ocorre independente da classe social que ela pertence.

Frequentemente a mulher violentada procura serviços de saúde por problemas com a saúde física ou mental, consequência da violência doméstica, porém os profissionais não conseguem fazer relação da procura ao serviço com a violência doméstica; não há uma percepção da "real" causa dos danos. Isso ocorre por diversos motivos, tais como: por falta de preparo, desinteresse, falta de tempo para escutar o paciente durante os atendimentos e foco somente nas lesões físicas (GARBIN et al, 2006).

Pelo fato de a violência doméstica ser considerada uma questão de saúde pública, há necessidade de ser identificada pelos profissionais de saúde (GARBIN et al, 2006). A falta de preparação dos profissionais em identificar os casos de violência doméstica no âmbito da saúde foi um dos motivos relevantes para se pesquisar o tema proposto, pois se há dificuldade em perceber quando ocorre a violência física, menor ainda será a possibilidade de perceberem a violência psicológica ou moral, pois não apresenta lesões visíveis.

Diante disso tem-se o questionamento: Como se caracteriza a violência doméstica a partir da percepção de mulheres violentadas? Para responder a este questionamento, o objetivo geral foi: Caracterizar a violência doméstica a partir da percepção de mulheres que sofreram violência doméstica. E ainda na percepção das mulheres violentadas, os objetivos específicos: identificar as formas de violência doméstica; identificar as causas em que geralmente levam as situações de violência doméstica; verificar as consequências físicas, psicológicas e sociais e identificar as estratégias de enfrentamento utilizadas perante a violência doméstica.

\section{Método}

A classificação da pesquisa quanto aos objetivos de estudo é descritiva, quanto à natureza é qualitativa, quanto ao corte é transversal e o delineamento é estudo de caso.

Foi realizado contato com os responsáveis pelas instituições (ONG e Centro de Referência de Atendimento à Mulher em Situação de Violência) da Grande Florianópolis, locais onde as mulheres que sofreram violência doméstica estavam vinculadas. Participaram desta pesquisa quatro mulheres da Grande Florianópolis, vinculadas às instituições de apoio as mulheres que sofrem violência doméstica. $O$ critério de inclusão foi que as mulheres tivessem passado por uma situação de violência nos últimos cinco anos e fossem maiores de 18 anos (Quadro 1).

\begin{tabular}{|c|c|c|c|c|c|c|c|}
\hline $\begin{array}{l}\text { Mu } \\
\text { lhe } \\
\text { res }\end{array}$ & Idade & $\begin{array}{l}\text { Estado } \\
\text { civil }\end{array}$ & Escolaridade & Profissão & $\begin{array}{l}N^{o} \\
\text { filhos }\end{array}$ & $\begin{array}{ll}\text { Tempo } & \text { de } \\
\text { relacionamento } & \end{array}$ & $\begin{array}{l}\text { Tempo de } \\
\text { violência }\end{array}$ \\
\hline M1 & 36 & Solteira & $2^{\circ}$ grau & $\begin{array}{l}\text { Tec. } \\
\text { Enfermagem/ } \\
\text { Desempregada }\end{array}$ & 1 & 8 anos & 8 anos \\
\hline M2 & 45 & Solteira & $1^{\circ}$ grau & $\begin{array}{ll}\text { Auxiliar } & \mathrm{de} \\
\text { produção } & \end{array}$ & --- & 3 anos & 1 ano \\
\hline M3 & 48 & Casada & $2^{\circ}$ grau & $\begin{array}{l}\text { Merendeira/ } \\
\text { Afastada }\end{array}$ & 3 & 10 anos & 6 anos \\
\hline M4 & 38 & Viúva & $2^{\circ}$ grau inc. & Cozinheira & 2 & 13 anos & 13 anos \\
\hline
\end{tabular}

Fonte: Elaboração da autora, 2013. 
A coleta de dados foi realizada na instituição que as mulheres frequentavam ou no domicílio dessas. Os dados foram coletados por meio de uma entrevista semiestruturada composta por dados de caracterização e dez perguntas relacionadas aos objetivos da pesquisa, com duração de aproximadamente quarenta minutos. A entrevista foi gravada com o consentimento das entrevistadas. As entrevistas realizadas foram transcritas e analisadas por meio da técnica de análise de conteúdo proposta por Bardin (2011).

\section{Resultado e discussão dos dados}

Os resultados e a discussão dos dados serão discutidos por meio das categorias de análise quais sejam: formas de violência, causas da violência, consequências físicas, consequências psicológicas, consequências sociais, estratégias de enfrentamento para diminuição da situação de violência.

\subsection{Formas de violência}

Fonseca e Lucas (2006) informam que a violência física é a mais comum entre as formas de violência. Essa informação vai ao encontro dos dados obtidos nesta pesquisa, pois entre todas as formas de violência citadas pelas mulheres que participaram da pesquisa, a violência física foi a mais recorrente, citadas por todas elas. De acordo com as entrevistadas, M1: "Depois começou a agressão muito mais forte, mais intensa, aqueles machucados, de deixar roxo, olho roxo, os dois olhos e isso foi me machucando porque imagina, a pessoa sai, te bate, te machuca, não conseguia às vezes nem andar de dor nas minhas pernas, que ele me chutava, puxava os meus cabelos (sic)" e M4: "Eu levei muita pancada na cabeça, cortou aqui dentro, esse osso aqui está estourado, ele me bateu muito, ele pegava minha cabeça e dava na parede, bateu aqui na porta várias vezes, tanto que tinha sangue na porta (sic)". Além de M1 e M4, M2 e M3 também referiram outros tipos de violência física, dentre elas: empurrões, chutes, apedrejamentos, brigas envolvendo faca, puxões de cabelo, socos, tapas e enforcamento. Esses atos são recorrentes na violência doméstica conforme indicam Narvaz e Koller (2006); Garbin et al (2006); Silva, Coelho, Caponi (2007); Day et al (2003); Fonseca e Lucas (2006).

A forma de violência patrimonial também é citada na fala de todas as entrevistadas e é entendida como qualquer violação de objetos ou documentos que pertencem à vítima (BRASIL, 2006). M3 demonstra em sua fala: "ele violava as minhas correspondências, chegava na caixinha ele pegava e rasgava tudo, pregava as janelas, tudo isso é uma violência patrimonial (sic)". As outras entrevistadas citaram também que os companheiros pregavam as janelas da casa, quebravam eletrodomésticos, móveis e objetos. Esta violência ocorria junto com as outras formas de violência e em outros ocorria isoladamente.

A violência sexual aparece na fala de duas mulheres (M1 e M2), relatada por M1: “Ah sim, ele me agredia, me forçava a ter relação [...] às vezes eu não queria ter relação com ele, ele me agredia fisicamente pra eu ter relação com ele [...] imagina a pessoa batendo no teu rosto e arrancando a tua roupa (sic)". Nessa fala é visível a ocorrência da violência física e sexual juntas. Day et al (2003, p.10-11) confirmam que a violência sexual se caracteriza como "toda ação na qual uma pessoa, em situação de 
poder, obriga uma outra à realização de práticas sexuais, utilizando força física, influência psicológica ou uso de armas ou drogas".

Outra forma de violência frequente nas entrevistas foi a violência moral, citada por todas as mulheres. Galvão e Andrade afirmam que a violência moral acontece "quando se trata de calúnia, difamação e injúria" (2004, p.93). Como foi apontada na fala de M3: "Ele mandava mensagem no celular me convidando pra fazer programa com ele (...) me desmoralizava, ligava pros meus irmãos, pra minha família, pros vizinhos, falando mentira de mim (sic)". De acordo com as falas das mulheres entrevistadas, a violência moral sempre ocorria ao mesmo tempo com a violência física, conforme a fala de M4: "Ele chegava: "e ai sua vagabunda, não vai falar nada"? E puxava o cobertor, "não vai falar sua vagabunda"? Me chutava (sic)". A violência moral nesse caso ocorria em forma de xingamentos e ofensas.

A violência psicológica, citada por três mulheres (M1, M3 e M4), "compreende queixas como tortura psicológica, ameaça verbal, indução ao suicídio, constrangimento ilegal [...]" (GALVÃO - ANDRADE, 2004, p.93). Este tipo de violência fica evidente na fala de M1: "Me chantageava, me ameaçava, me mandava embora porque sabia que eu não tinha pra onde ir, pra mim é uma violência total (sic)". Galvão e Andrade (2004) apontam em sua pesquisa que em primeiro lugar está a violência psicológica/emocional com $56,4 \%$ e em segundo a violência física com $32,1 \%$ das 470 fichas analisadas na pesquisa (do Centro de Atendimento à Mulher de Londrina/PR). Os autores apresentam vários comportamentos, que caracterizam a violência psicológica, dos agressores em relação às mulheres como: ridicularizar a vítima, gritar, culpar por tudo de errado que acontece, humilhar, contar sobre relacionamentos que mantêm fora do casamento e criticar a família da mulher, com isso amedrontando-a e levando-a ao desespero. Esses autores constataram a violência psicológica como a mais recorrente, o que difere na presente pesquisa, pois nesta a violência psicológica aparece na fala de três mulheres e ocorria em menor frequência em relação à violência moral e física.

Diante desses dados nas situações de violência doméstica discute-se se há possibilidade de ocorrer a violência física sem a ocorrência da violência psicológica? Deeke, Boing e Oliveira (2009) confirmam que a violência física presente nos relacionamentos, geralmente ocorre junto com a violência psicológica. Em uma pesquisa realizada no Rio de Janeiro por Acosta e Barker (2003) apontou que as formas violência física (cometida por $25,4 \%$ dos homens) e psicológica (cometida por $38,8 \%$ dos homens) foram utilizadas contra a companheira pelo menos uma vez na vida. Ainda respondendo ao questionamento, podemos ancorar aos achados de Gadoni Costa, Zucatti e Dell'aglio (2011) que constataram que nas situações que ocorre a violência física e sexual, aparece também a violência psicológica, pois ocorrem juntas e em diferentes situações. Percebe-se assim que a violência psicológica, em grande parte das situações, ocorre concomitante com a violência física.

É possível perceber que a violência moral, muitas vezes é confundida com a violência psicológica, por esse motivo, pode ter sido menos citada pelas mulheres, que não faziam a diferenciação entre violência psicológica e moral. A violência doméstica envolve todas as formas citadas pela lei, elas aparecem interligadas, como se uma forma de violência causasse a outra forma e assim por diante. No entanto nas entrevistas, quando perguntado às participantes qual a percepção delas sobre a violência doméstica, 
elas caracterizavam somente como violência física. Somente quando foram questionadas sobre quais tipos/formas de violência sofreram é que mencionaram as outras, além da física.

Diante disso, pode-se refletir que o motivo de a violência psicológica ter sido menos citada se dá pela importância atribuída aos danos físicos, por serem visíveis e mais fáceis de identificar. Outro motivo que pode ter contribuído para esse aspecto, é o fato de que a violência física nas situações de violência doméstica é tão frequente e intensa que com isso a violência psicológica acaba sendo mais uma ofensa, xingamento, muitas vezes preferível a um tapa, soco ou chute e por isso passa despercebida, conforme relata M2: "quando bebia xingava, mas era bem menos, mas também aquele negócio de vagabunda que eu já nem, pra mim, acabava acostumando (sic)”.

Nesta pesquisa também foi possível verificar que a decisão de denúncia era motivada a partir da violência física, pois de acordo com as participantes, as fazia pensar na possibilidade de serem assassinadas. Foi a partir de uma situação de violência física extrema, em que três das mulheres (M1, M2 e M4) resolveram chamar a polícia, fazendo a denúncia, sendo que após a denúncia de M4, o companheiro acabou morrendo por um desentendimento entre ele e a polícia; M1 e M2 saíram de casa e permaneceram em uma ONG temporariamente. Fernandes (2012) confirma que as mulheres em situação de violência só denunciam o agressor quando são ameaçadas com armas de fogo, quando as agressões resultam em fraturas, cortes e espancamento contra si ou contra os filhos e ameaçadas de morte.

\subsection{Causas da violência doméstica}

Entre as causas listadas pelas mulheres citaram a droga lícita ${ }_{2}$ em específico o álcool, citada por duas mulheres (M2 e M4), e a droga ilícita citada novamente por (M2) (que mencionou que a droga que o ex-companheiro fazia uso era o crack) e por M1 que não mencionou o tipo de droga que o companheiro utilizava. As participantes referiram que as situações de violência ocorriam sob uso de substâncias. Essa informação é confirmada na pesquisa realizada por Deeke, Boing, Oliveira (2009) constatando que " $30 \%$ dos homens faziam uso de álcool antes ou depois das situações de violência" (p. 253).

No estudo de Melo, Silva e Caldas (2009) em aproximadamente 40\% dos casos de violência (total de 37 casos), a causa para a violência doméstica era pela pretensão da mulher de desfazer a relação, devido ao consumo de bebidas alcoólicas e também pelo ciúme. Nesta pesquisa a separação também foi constatada como causa da violência doméstica, relatada por (M3): "Logo depois da separação que veio os conflitos maiores, ele partiu pra agressão, logo depois que ele saiu de casa, antes tinha conflitos, mas não violência (sic)"'. É possível perceber na fala de M3, que quando ela decidiu se separar do companheiro, esse não aceitava, partindo para a agressão. M3 e o marido ficaram casados por dez anos, sendo que após os primeiros quatro anos, houve separação de corpos e durante os seis anos seguintes o marido permaneceu realizando as agressões, pois morou próximo a casa da mulher. M3 deixou claro na entrevista que antes da separação de corpos não houve violência, ou seja, confirma-se a separação como causadora da violência, nessa situação.

Entre as causas de violência o ciúme é apresentado por Melo, Silva e Caldas (2009), como umas das causas da violência doméstica. Nesta pesquisa o ciúme foi 
citado por duas mulheres (M1 e M2). Vale ressaltar que na fala das duas entrevistadas o ciúme era do tipo patológico, ou seja, o ciúme patológico corresponde a uma preocupação excessiva, o sujeito deseja ter controle total dos pensamentos, sentimentos e comportamentos do parceiro, há preocupação com relações amorosas do passado e desconfiança excessiva. Com isso o ciúme patológico acarreta prejuízos para a relação (ALMEIDA, RODRIGUES e SILVA, 2008). De acordo com as falas das mulheres, o companheiro não admitia que elas tivessem relacionamento com outras pessoas, seja com os amigos, a família ou os vizinhos. M1 relata que o companheiro era possessivo, dando a entender que a mulher pertencia somente a ele. Nas situações em que o ciúme acontece de forma exagerada, pode ocorrer o ciúme patológico e acarretar o adoecimento no relacionamento amoroso (GUIMARÃES, 2012).

A cultura familiar também foi citada por uma mulher como causa da violência doméstica, conforme relata M4: “criação, porque ele foi criado assim”. Nessa fala M4 se refere à cultura familiar do agressor, que segundo o relato da participante, ele presenciou cenas de violência quando criança, na família, como também aprendeu que o homem tinha privilégios em relação à mulher, tendo uma visão de educação diferenciada entre homens e mulheres. A educação diferenciada entre homens e mulheres está relacionada a cultura patriarcal, onde ocorre a aprendizagem dessas diferenças, através das famílias, escolas, igrejas e meios de comunicação. Assim é ensinado às crianças, desde o nascimento, as características de uma mulher: ser passiva, submissa, subordinada, obediente e de um homem que por sua vez: deve ser poderoso, dominador, viril, agressivo. Essa educação diferenciada reproduz uma desigualdade em relação ao comportamento dos homens e mulheres, possibilitando a dominação da mulher pelo homem, inferiorizando a mulher e priorizando o homem, com isso, em muitos casos, gerando a violência doméstica (SILVA, 1992; BRAGHINI, 2000; GALVÃO e ANDRADE, 2004; FONSECA e LUCAS, 2006; GOMES et al, 2007).

Braghini (2000) ainda afirma que há uma série de violências no dia-a-dia do casal, que se repercute continuamente como um ciclo.

O grau de tensão da relação vai aumentando gradativamente, até que fica insuportável, e então, por um motivo aparentemente banal, o homem explode agredindo violentamente a companheira. [...] Por certo tempo, movido pela culpa e pelo medo de perdê-la, ele "veste pele de cordeiro", e consegue fazer o papel do bom marido. Mas, à medida que a tensão começa a se acumular novamente, fica muito difícil desempenhar este papel, até que há outra explosão, e o ciclo se repete (BRAGHINI, 2000, p.19).

O ciclo da violência possui três períodos: a primeira fase de tensão, caracterizada pela violência moral e psicológica; a segunda fase marcada pelas agressões físicas; e a terceira fase da "lua de mel, onde o casal realiza promessas mútuas, ocorre uma idealização do parceiro e a negação da vivência de violência" (PORTO, 2004, p.67). De acordo com as entrevistas, o ciúme e a cultura familiar foram motivos atribuídos pelas mulheres que motivavam o companheiro a cometer a violência.

A pesquisa de Rangel e Oliveira (2010) mostra que os fatores motivadores da violência ultrapassam a quantidade de vítimas, pois a mesma mulher é agredida por mais de uma causa. Nesta pesquisa, este aspecto se fez presente, parte das mulheres 
entrevistadas identificaram mais de um fator motivador da violência doméstica. M1 e M2 citaram drogas e ciúme, M4 citou álcool e cultura familiar como causa das violências.

\subsection{Consequências físicas da violência doméstica}

Segundo Fonseca e Lucas (2006) a violência doméstica traz consequências nos aspectos físicos, emocionais, cognitivos, sociais e morais, podendo o dano ser imediato ou não. Na pesquisa realizada pelas autoras "Violência doméstica contra a mulher e suas consequências psicológicas", na qual foram entrevistadas 25 mulheres, essas citaram alguns tipos de consequências por sofrerem violência doméstica, entre elas foram relatadas:

Insônia, perda de concentração, pesadelos, irritabilidade, falta de apetite, dores no corpo, principalmente de cabeça, aumento da pressão arterial, depressão, ansiedade, síndrome do pânico, estresse póstraumático assim como o uso do álcool e drogas ou até mesmo tentativa de suicídio (FONSECA - LUCAS, 2006, p. 11-12).

Nos relatos das entrevistadas se fizeram presente os problemas de saúde relacionados às consequências físicas da violência doméstica e foram apontados por três mulheres (M1, M3 e M4), evidenciados na fala de M3: "sim eu estou afastada do trabalho dois anos por pressão alta e problema no coração (sic)". Além destes, as mulheres relataram: dor abdominal, dor nas pernas e disfunção alimentar. Os problemas de saúde também são apontados pela literatura, como "dor de cabeça, problemas digestivos, distúrbios alimentares, depressão, hipertensão arterial" (VIEIRA et al, 2009, p. 568). As consequências na saúde podem ocorrer a curto ou a longo prazo, sendo relacionados ou não com a violência sofrida.

As fraturas também estão relacionadas às consequências físicas e foram citadas por duas mulheres entrevistadas. M1: "ele quebrou meu nariz (sic)" e M3: "Eu levei muita pancada na cabeça, cortou aqui dentro, esse osso aqui está estourado [ela mostrou a boca] (sic)". Garbin et al (2006) apontam "a região de cabeça e pescoço a mais atingida como consequência de agressões físicas, resultando em fraturas, contusões, queimaduras" (p. 2569). A escolha do agressor por essas regiões, segundo os autores, imprime a humilhação na mulher quando atinge seu rosto, com a intenção de tornar evidente a agressão em relação à sociedade e prejudicar a beleza feminina que é tão valorizada socialmente. Segundo Galvão e Andrade (2004) as mulheres vítimas de violência acabam tendo como consequência a saúde prejudicada, causadas por lesões devidas, muitas vezes a espancamentos.

Outra consequência física identificada na pesquisa foi em relação às marcas no corpo, citadas pelas quatro mulheres entrevistadas. As marcas no corpo se caracterizaram por hematomas, manchas roxas e cortes. M2 relata: "me deu um corte no braço [...] tenho até a marca, me cortei toda com uns cacos de vidro que ele quebrou [...] fiquei com um roxo nas pernas e os dois braços com hematomas (sic)". Simião (2006) aponta que quando as agressões físicas resultam em sangramento ou sequela física é considerada pelas mulheres, mais grave e assim menos aceita do que quando a violência resulta em hematomas ou marcas no corpo. 
Pode-se perceber que os problemas de saúde e marcas no corpo se apresentam como um primeiro estágio da violência física começando aos poucos até chegar ao ponto máximo, que no caso das mulheres entrevistadas foram fraturas; a última fase desse ciclo da violência poderia ser a morte delas. As mulheres entrevistadas relataram que poucas vezes procuraram os serviços de saúde, sendo que quando houve a procura, os problemas de saúde e fraturas não foram identificados pelos profissionais, como consequências em decorrência das situações de violência. Porto (2004) aponta que os profissionais não procuram saber a causa dos ferimentos, em muitos casos podem até hipotetizar, porém, como na maioria das vezes, não sabem lidar com a situação, preferem não questionar e prestar atendimento somente naquilo que lhe compete, ou seja, minimizar as sequelas físicas.

\subsection{Consequências psicológicas da violência doméstica}

Galvão e Andrade (2004) mencionam que as mulheres agredidas têm mais tendências a desenvolverem disfunções psicológicas em relação às mulheres que não sofrem violência doméstica. Uma consequência psicológica é o rebaixamento de humor, citado por três mulheres (M1, M3 e M4). "Depressão e eu estava no fundo do poço já, quando aconteceu eu tava mesmo, porque não tinha mais vida nenhuma (sic)" (M4). As mulheres citaram a depressão como consequência psicológica, mas não explicaram se foram diagnosticadas com depressão, com isso, a pesquisadora utilizou o termo rebaixamento de humor. O sofrimento psíquico e seu efeito cumulativo podem vir a desenvolver doenças psicossomáticas variadas; a depressão, por exemplo, é a mais comum. Esta é uma doença recorrente na atualidade e os aspectos estressantes no ambiente doméstico são considerados uma das causas. Esse rebaixamento de humor acaba influenciando o bem-estar e o desenvolvimento da saúde psicológica da mulher (FONSECA; RIBEIRO; LEAL, 2012). Durante as entrevistas, as participantes relataram se sentirem sozinhas, depressivas, no "fundo do poço", com pensamentos negativos e sem vontade de viver.

A baixa autoestima foi citada por apenas uma mulher, que disse: "acabou comigo como pessoa (sic)" (M4). Segundo Vianna, Bomfim e Chicone (2006) o ser humano, além de satisfazer as necessidades fisiológicas, necessidades de segurança, também precisa satisfazer as necessidades de estima "relacionadas ao amor próprio, autoestima, auto-respeito, confiança necessidade de reconhecimento, apreciação e admiração" (p.49). Quando uma pessoa satisfaz as necessidades de autoestima, se sente mais confiante, ocorrendo o contrário, a não satisfação dessas necessidades, surge no sujeito "sentimentos de inferioridade, fraqueza e impotência" (p.49). Ainda segundo os autores a permanência desses sentimentos causa problemas psicológicos, pois é necessário se sentir seguro, para que a autoestima continue elevada. Nas situações de violência, as mulheres eram ofendidas, humilhadas, ameaçadas, com isso se sentiam diminuídas e com a autoestima baixa. Os agressores utilizam dessa tática com objetivo de difamar a imagem da mulher, pois com a autoestima baixa, a mulher se sente desvalorizada e desamparada (VIANNA; BOMFIM; CHICONE, 2006).

A perda de libido foi apresentada por uma mulher, M1: "sexualmente, eu perdi totalmente o interesse sexual por ele, eu não queria mais ter relação com ele, quando começaram nossas brigas maiores, porque ele queria ter relação e eu não sentia mais prazer nenhum, não sentia prazer nem às vezes de tratar ele bem (sic)". Na 
mesma direção, Souza et al (2012) apontam que podem surgir transtornos da sexualidade, diminuição da lubrificação vaginal e perda do orgasmo ou até mesmo a total aversão ao sexo. Mulheres que passam por uma situação de violência sexual podem apresentar indicadores de danos psicológicos como os distúrbios sexuais. M1 sofreu violência sexual, além das outras formas de agressão.

O medo como uma das consequências psicológicas aparece na fala de duas mulheres (M1e M4): eu tinha muito medo dele "[...] eu tinha medo de ele fazer algum mal mesmo, bem feio pra mim (sic)" (M1). Narvaz e Koller (2006) apontam que o medo e a insegurança são causados pelas intimidações do agressor e pela violência psicológica. "O medo prevalece em relação aos demais motivos de denúncia" (FERNANDES, 2012, p.21). O medo é um aspecto recorrente entre as mulheres que sofrem violência doméstica e contribui para que essas não se percebam como um indivíduo possuidor de direitos. Ele contribui para que a vítima não tenha capacidade crítica e compreenda a condição passiva. "O medo institui na mulher a baixa autoestima, a vergonha, e o não auto-respeito, deixando graves sequelas, não somente no corpo, mas principalmente na alma das mulheres" (CZAPSKI, 2012, p.321). Na fala das mulheres foi possível perceber o medo que tinham em relação ao agressor, esse motivo pode ter levado a permanência delas com os agressores por mais tempo. O medo era quase que diário, pois não sabiam quando o parceiro iria decidir agredi-las novamente. As mulheres tinham medo da próxima agressão, medo de que o agressor fizesse algo contra os filhos e até mesmo da morte. Fonseca e Lucas (2006) também apontam a questão da insegurança e do medo, as mulheres sempre imaginam ou pensam no momento em que o agressor pode voltar a agredi-las como também proibir a realização de atividades de lazer, com amigos e família.

Além das decorrências de disfunções citadas, foi também relatada a mágoa. Foi relatada por duas mulheres (M1 e M2), conforme cita M1: "isso foi se tornando uma bola de neve e aquilo foi me magoando, me machucando [...] magoava muito, me machucava e aquilo foi me deixandomuito mal (sic)". De a cordo com Silva et al (2007) a relação permeada pela violência doméstica, mesmo após o término deixa questões não resolvidas, com isso resulta em mágoa. Em alguns casos, as relações são permeadas por um laço afetivo atravessado por mágoas, que impossibilita a vítima de perceber a situação de violência. M1 e M2 relatam estarem magoadas com toda agressão que sofreram do ex-companheiro, com isso se sentiam machucadas, a cada situação de agressão, sendo física ou não, a mágoa crescia e se acumulava. Conforme os relatos, esse sentimento de mágoa permaneceu mesmo após o término da relação.

Outra consequência psicológica que se fez presente nos relatos das participantes da pesquisa foi a raiva, citada por duas mulheres (M2 e M3). Segundo Ekman (2011)

a raiva abrange diversas experiências afins. Há uma variedade de sentimentos de raiva, desde o aborrecimento leve até a fúria. Não há só diferença na força dos sentimentos, mas também no tipo de raiva. A indignação é a raiva farisaica; o mau humor é a raiva passiva; a exasperação refere-se a ter a paciência provada em excesso. A vingança é um tipo de ação furiosa cometida, em geral, após um período de reflexão a respeito da ofensa, às vezes com maior intensidade que o ato que a provocou (EKMAN, 2011, p.127). 
M2 afirmou ter uma revolta em relação aos homens, por causa das agressões que sofreu e M3 diz também ter uma revolta, dor e decepção em relação ao ex-marido. Pode-se verificar a partir das entrevistadas que a raiva era presente na relação por causa das agressões e após o término da mesma ela permanecia.

A questão da falta de paciência também foi relatada por duas mulheres (M2 e M4). Pode-se verificar a partir da fala de M4: “[...] eu me tornei uma pessoa assim, eu não tolero mais nada, eu meto a boca se for preciso [...] se alguém vem, nem precisa discutir, eu já discuto (sic)". De acordo com as entrevistadas, devido às situações de violência que sofreram, hoje se percebem intolerantes e impacientes. M2: "eu sou uma pessoa ignorante hoje em dia até com as pessoas, eu não sou mais a pessoa que eu era, não sou mesmo, eu já fui assim, bem tranquila. Tu gritou comigo eu já me altero (sic)". Com isso é possível perceber a partir das falas que a revolta pelas situações de violência, devido ao intenso sofrimento, causado pela violência, as mulheres começaram a perder a paciência em situações distintas.

\subsection{Consequências sociais da violência doméstica}

As agressões que as vítimas de violência sofrem trazem prejuízos físicos, psicológicos e também sociais (VIEIRA et al, 2009). No que tange aos prejuízos sociais duas mulheres (M1 e M2) relataram diminuição do convívio com a família. De acordo com M1: "[meu pai] meio que me deixou de lado por causa dessas violências (sic)". Esta fala explicita que a família muitas vezes se afasta das mulheres vítimas de violência pelo fato de não aceitarem a situação e até, em alguns casos, como citado pela própria M1 o companheiro ter agredido seus familiares. A diminuição do convívio com os amigos também está presente nos relatos das mulheres entrevistadas, citadas por três vítimas (M1, M2 e M4): “até as minhas amizades, que eram só minhas amigas, elas me consideravam igual, mas não era a mesma coisa, elas me procuravam, mas não dava pra se misturar (sic)" (M4). "Mulheres vítimas de violência geralmente estão isoladas da rede de parentesco e da comunidade, o que facilita o controle do agressor sobre a vítima" (NARVAZ e KOLLER, 2006, p. 10). Os autores também apontam que a falta de apoio social e da família constituem-se como um dos motivos que levam a vítima a permanecer com o agressor, o que dificulta a denúncia dos mesmos.

Quando M1 explicita em sua fala que "quando acontecia as situações de violência, eu não queria sair de casa, porque eu tinha vergonha dos vizinhos - ah aquela ali apanha do marido - eles caçoavam (sic)" é possível evidenciar outra consequência social da violência doméstica: a vergonha em relação às outras pessoas. A vergonha da situação violência sofrida é um dos aspectos que impede a busca de suporte na família e amigos, com isso dificultando que as situações de violência cessem (NARVAZ e KOLLER, 2006). Fonseca, Ribeiro e Leal (2012) apontam que as vítimas de violência doméstica frequentemente negam, omitem e escondem a situação, evitam sair de casa, limitam-se socialmente, reduzindo as amizades e vivendo em condições de confinamento. Três entrevistadas relataram durante as entrevistas terem vergonha dos vizinhos que sabiam ou presenciavam as situações de violência. Outro fator que colaborava para que a mulher se isolasse e permanecesse mais tempo dentro de casa. 
O julgamento social aparece na fala de duas mulheres (M1 e M4). Elucidado no relato de M1: "a sociedade te recrimina muito sobre isso, porque às vezes a gente é tratada assim: ah aquela ali gosta de apanhar, só que não é assim [...] as pessoas julgam muito (sic)". A violência doméstica traz consequências como a vergonha das agressões, violação da privacidade e também a culpa por não conseguirem resistir à violência sofrida (SANTI, NAKANO, LETTIERE, 2010). Desse modo percebemos que a vergonha e o julgamento são fatores que contribuíram para que as mulheres se isolassem ainda mais e sofressem caladas.

$\mathrm{O}$ afastamento do trabalho foi relatado por uma mulher, M3: "sim eu to afastada do trabalho há dois anos (sic)”. M3 teve consequências físicas e psicológicas da violência e em virtude disso também precisou se afastar do trabalho. "No mundo, um em cada cinco dias de absenteísmo no trabalho feminino decorre da violência doméstica" (ADEODATO et al, 2005, p.109). Sobre o afastamento do trabalho, a Lei 11.340 ( Lei Maria da Penha) prevê em seu Art. 9 que será mantido o "vínculo trabalhista, quando necessário o afastamento do local de trabalho, por até seis meses" (BRASIL, 2006). O guia trabalhista ainda aponta que há possibilidade de os juízes concederem o afastamento da empregada em situação de violência doméstica ou familiar, se caracterizando como afastamento por auxílio-doença, que foi o caso da entrevistada M3, que se afastou por motivo de pressão alta e problema no coração (GUIA TRABALHISTA, 2013). Não foram encontradas literaturas que discutam o afastamento do trabalho decorrentes de situações de violência doméstica; pode- se dizer que não se discute muito sobre o tema, pois o afastamento do trabalho é registrado relacionando a condição de saúde do trabalhador e não necessariamente o que ocasionou o afastamento.

\subsection{Estratégias de enfrentamento para diminuição da situação de violência}

As estratégias de enfrentamento para diminuição da situação de violência diz respeito à conduta das mulheres com o objetivo de diminuir o sofrimento e a ocorrência da violência doméstica. Em pesquisa realizada por Silva et al (2012) os autores constataram que a maioria das mulheres entrevistadas tiveram alguma atitude em relação às situações de violência doméstica.

$\mathrm{Na}$ presente pesquisa a subcategoria pedir auxílio à outrem aparece como estratégia tanto para diminuição do sofrimento, como para diminuição das situações de violência doméstica. Na fala de uma mulher, M3 explicita que busca auxílio nos profissionais da saúde, para diminuir seu sofrimento: "eu fui no postinho e tinha apoio do pessoal do postinho, da psicóloga, tinha uma doutora muito boa lá (sic)". Adeodato et al (2005) constataram em sua pesquisa que algumas das mulheres que eles entrevistaram procuraram auxílio em algum Centro de Saúde. Porto (2004) afirma que as mulheres que sofrem violência doméstica procuram os serviços de saúde com frequência, sendo que mesmo havendo a procura, elas omitem a violência sofrida, alegando outros motivos para as lesões. $\mathrm{O}$ autor ainda cita que mulheres que sofrem violência doméstica utilizam o serviço de saúde com frequência (PORTO, 2004). Nesse caso o pedido de ajuda foi em um Centro de saúde, sendo que M3 tinha apoio familiar e social, acredita-se que esse aspecto facilitou que ela procurasse ajuda profissional. De acordo com as mulheres entrevistadas, foi possível perceber que elas procuram com frequência os serviços de saúde, por motivo dos danos físicos e não por problemas 
psicológicos, com intenção de diminuir o sofrimento causado pela violência doméstica, sendo que a queixa se inicia pelo dano físico, por um aspecto mais perceptível e fácil de falar. Nesta pesquisa, a procura foi citada por apenas uma das quatro mulheres. $\mathrm{O}$ pedido de auxílio a outrem também aparece no relato das vítimas, em relação a quem elas recorriam no momento de ocorrência das situações de violência, citada por três mulheres (M1, M3 e M4): "Geralmente eu chamava a polícia, e a polícia foi uma ou duas vezes (sic)" (M3). "Eu tenho vários boletins de ocorrência dele, nove, dez [...] porque eu já procurei quando a gente tava namorando várias vezes a polícia (sic)” M1. Os autores Silva et al (2012) corroboram que o serviço mais procurado pelas mulheres é a polícia/delegacia. Deeke et al (2009) procuraram em sua pesquisa saber onde as mulheres buscavam ajuda e verificaram que procuravam familiares, amigos, vizinhos e a polícia. Durante as entrevistas, M4 relatou ter procurado a família do companheiro e a polícia, M1 pediu socorro no momento das agressões e chamou a polícia em algumas situações, M3 também relatou ter chamado a polícia por várias vezes e ter recorrido à mídia, foi o momento em que se deu a prisão do ex-marido. Percebe-se que quando as mulheres pediam auxílio a alguém é porque não suportavam mais e não sabiam como agir diante dessas situações.

Diminuição do tempo de interação/convivência com o agressor é citada por uma mulher. M4: "Eu sempre fujo dos problemas, qualquer coisa eu me escapo, não sou de enfrentar, por isso que vivi esses anos todos com ele, porque eu fugia do problema, sempre fugi [...] aí eu me lembro que ele (filho) quando era pequeno, a gente fingia muito que dormia, pra não se incomodar, vê se isso é vida [...] Porque eu sei que é um erro [...] eu sei que não é normal, que eu fujo do problema, todo mundo acha uma fuga né, [...] trabalhava, trabalhava, trabalhava, final de semana pegava os meus filhos ia pra praia (sic)". Faria e Seidl (2005) afirmam que o enfrentamento focado na emoção tem como objetivo adequar a resposta emocional originada pela situaçãoproblema, apresentando comportamentos de afastamento, negação ou esquiva. M4 demonstrou durante a entrevista que focava sempre em outras atividades para, assim, evitar permanecer mais tempo em casa com o companheiro; tal como no trabalho, quando cita que as vezes tinha dois ou três empregos, ou ainda fingia que estava dormindo, junto com os filhos, para evitar conflitos com o companheiro e uma possível agressão. No que se refere a diminuição do tempo de interação/convivência com o agressor, não foram encontrados referências a respeito do assunto; as literaturas encontradas só referem o afastamento do agressor do lar, quando é determinada a medida protetiva.

A separação apareceu na fala de duas mulheres (M2 e M4), "eu saí, mas eu saí pra casa de uma colega [...] e fiquei lá três dias, depois ele descobriu onde que eu tava, dai pediu desculpas tal, daí voltei (M2) (sic)". Silva et al (2012) verificaram em sua pesquisa que $32,1 \%$ das mulheres saíram de casa em algum momento e os motivos básicos citados foi por não suportarem mais as situações de violência, por terem ficado muito machucadas ou com medo de serem mortas. A fala das mulheres confirma que elas tiveram coragem em sair de casa, desejavam a separação no momento em que saíram, mas acabaram retornando a pedido do companheiro ou por perceberem que mesmo praticando as agressões, o companheiro era uma boa pessoa.

Silva et al (2012), em sua pesquisa com 283 mulheres gestantes vítimas de violência, constataram que a maioria das mulheres já agrediram seus parceiros com 
objetivo de se defenderem. A defesa foi citada durante as entrevistas por todas as mulheres. M2: “[...] no começo [...] eu tinha até pena, mas depois começou a me dar uma gana, uma raiva e quebrava o pau [...] quando eu via que ele ia vir me agredir eu também me defendia (sic)". Nas falas das mulheres percebe-se que elas em alguns momentos se defendiam, partindo para a agressão também, quando não agrediam, discutiam ou tentavam se defender de alguma outra forma. Porto (2004) afirma, a partir das constatações em sua pesquisa que nas situações mais graves de violência algumas mulheres relataram tentar se defender do parceiro, "embora seus relatos constatassem a expressão de impotência frente à força física masculina" (PORTO, 2004, p.73). Ainda segundo a autora, as mulheres descreveram que em muitos momentos era pior tentar se defender ou enfrentar, pois provocava mais violência.

A subcategoria ficar quieta foi citada por apenas uma mulher: "Pra ninguém ver e ele mandava eu ficar quieta, "não grita, não faz isso, não chora", aquela coisa [...] Eu ficava muito quieta, porque eu tinha medo que me agredisse mais ainda [...] eu ficava quieta, ou às vezes só falava "não me bate, isso vai ter consequências (sic)" (M1), que utilizava essa estratégia para evitar que a agressão fosse ainda pior, ela permanecia em silêncio e fazia o que ele ordenava. Na pesquisa de Fonseca, Ribeiro e Leal (2012), a passividade é apresentada como uma das reações das mulheres que sofrem violência doméstica. Essa "aparente" passividade das mulheres que sofrem violência, geralmente é compreendida como aceitação da situação que se passa, sendo que "essa passividade (paralisação) nasce do pânico frente ao agressor e ao medo da morte" (NARVAZ; KOLLER, 2006, p.10). Já Levine (1999) complementa dizendo que "todos os que sofrem de trauma experienciam, em algum grau, o fenômeno da impotência crônica. Qualquer fuga ou movimento adiante é praticamente impossível para as pessoas que experienciam a impotência e se identificam com ela" (LEVINE, 1999, p.143). A passividade ou paralisação frente ao trauma, no caso a situação de violência doméstica, seria por uma impotência que a vítima apresenta em relação à agressão. A questão da passividade vai ao encontro do comportamento de M1 em ficar quieta diante das agressões, entende-se que ela tem esse comportamento, não por aceitar a situação, mas sim para que as agressões não fossem ainda piores, com intenção de realmente diminuir a agressão sofrida.

A religiosidade também apareceu como estratégia de enfrentamento da situação de violência, citada por duas mulheres (M1 e M4). M1 relata: "ele chegava em casa, eu já pegava minha bíblia e ia orar -meu Deus, tomara que não aconteça nada, [...] imagina tu ter um marido que tem que pegar uma bíblia pra rezar pra que ele não quebre alguma coisa dentro de casa, pra que ele não te agrida (sic)". Conforme citam Faria e Seidl (2005), estudos afirmam que entre as estratégias de enfrentamento utilizadas está a procura de práticas religiosas para tentar lidar com as situações de conflito. Ainda segundo os autores, "as estratégias cognitivas ou comportamentais para lidar com os eventos estressores, advindas da religião [...], foram definidas como enfrentamento religioso" (FARIA - SEIDL, 2005, p.383). A religião tem várias funções para o enfrentamento do problema: "alívio, conforto e consolo" entre outras (FARIA SEIDL, 2005, p. 383). Essa estratégia trazia um conforto a elas, foi a maneira que encontraram para que pudessem se sentir consoladas ou aliviadas de alguma forma. Ao mesmo tempo M4, por exemplo, relata que pedia à Deus que resolvesse a situação e guiasse os caminhos dela. 


\section{Considerações finais}

Foi possível concluir que apesar da progressiva independência conquistada pelas mulheres na sociedade moderna, a violência doméstica é um fenômeno que ainda se faz presente. Constatou-se, ainda, que as mulheres justificavam de diversas maneiras a permanência com o agressor, mas em outros momentos das entrevistas elas relatavam que não identificavam o motivo que as fazia permanecer na situação de violência, sendo que o parceiro apresentava momentos de arrependimentos e promessas de que mudaria seu comportamento, fazendo-as acreditar que as situações de violência fossem cessar. As mulheres também permaneciam nessas situações muitas vezes por medo das ameaças, o que as fazia permanecer "presas" ao agressor e em frequente sofrimento.

Foi possível identificar os motivos que levavam às situações de violência como: droga lícita e ilícita, ciúme, separação, cultura familiar. As consequências da violêcia doméstica contra as mulheres tem o caráter físico, social e psicológico, atingindo essas mulheres em todas os aspectos. Com isso a violência doméstica pode ser considerada um problema de saúde pública, um problema social e econômico, por isso a necessidade da atuação de todos os profissionais da saúde, segurança pública e justiça.

A partir dessa pesquisa, verificou-se a necessidade de uma orientação/treinamento aos profissionais da saúde, que recebem as mulheres em situação de violência nas Unidades Básicas de Saúde e em hospitais, pois não sabem como agir diante da situação e não possuem preparação para isso. Com isso essas mulheres não têm um acolhimento adequado e muito menos um campo de escuta quando recorrem a esses locais com problemas de saúde ou psicológicos devido à violência doméstica. O psicólogo pode auxiliar na orientação a esses profissionais e nas situações de atendimento a essas mulheres, o profissional pode intervir na direção de um empoderamento, para que elas possam se reconhecer na situação de violência, deixar o papel de vítima e subordinação e assim conseguirem cessar com a violência sofrida. Se houver o acolhimento adequado dessas vítimas pelos profissionais, nesses locais, elas podem se sentir mais seguras para decidirem denunciar o agressor e sair da situação de sofrimento.

\section{Referências}

ACOSTA, F; BARKER, G. Homens, violência de gênero e saúde sexual e reprodutiva: um estudo sobre homens no Rio de Janeiro/Brasil. Rio de Janeiro: Instituto Promundo e Instituto NOOS, 2003.

ADEODATO, V. G.; CARVALHO, R. dos R.; SIQUEIRA, V. R. de; SOUZA, F. G. de M. Qualidade de vida e depressão em mulheres vítimas de seus parceiros. Rev. Saúde Publica, 2005, 108-113. Disponível em: http://webcache.googleusercontent.com/search?q=cache:PzZiRZc3gXQJ:www.scielo.br $/$ pdf/rsp/v39n1/14.pdf+\&cd=2\&hl=pt-BR\&ct=clnk\&gl=br. Acesso em: 10 out. 2013. ALMEIDA, T. de; RODRIGUES, K. R. B.; SILVA, A. A. da. O ciúme romântico e os relacionamentos amorosos heterossexuais contemporâneos. Estudos de Psicologia (Natal), 2008, 83-90. Disponível em: http://www.scielo.br/pdf/epsic/v13n1/10.pdf. Acesso em: 25 abr. 2014. 
BARDIN, L. Análise de conteúdo. São Paulo: Edições 70, 2011.

BRAGHINI, L. Discussões temáticas. In: BRAGHINI, L. Cenas repetitivas de violência doméstica: um impasse entre Eros e Tanatos. São Paulo: Unicamp, 2000.

BRASIL. Central de atendimento à mulher - Ligue 180. Relatório Trimestral 2012.

Disponível em: http://www.inesc.org.br/noticias/biblioteca/textos/relatorio-180/at download/file. Acesso em: 25 mar. 2013.

BRASIL. Lei Maria da Penha. Lei n. 11.340. Brasília, 2006. Disponível em: http://www.planalto.gov.br/ccivil_03/_ato2004-2006/2006/lei/111340.htm. Acesso em: 24 mar. 2013.

CZAPSKI, A. R. S. O assistente social no atendimento à violência doméstica contra a mulher. Revista Travessias, Ed. XIV, 2012. Disponível em: http://erevista.unioeste.br/index.php/travessias/article/view/5672. Acesso em: 10 out. 2013.

DAY, Vivian Peres, et al. Violência doméstica e suas diferentes manifestações. Rev. Psiquiatr. Rio Gd. Sul, Porto Alegre, v.25, p. 9 - 21, 2003. Disponível em: $<$ http://www.scielo.br/scielo.php?script=sci_arttext\&pid=S0101-

81082003000400003\&lng=en\&nrm=iso>. Acesso em: 20 mar. 2013.

DEEKE, L. P.; BOING, A. F.; OLIVEIRA, W. F. de; COELHO, E. B. S. A dinâmica da violência doméstica: uma análise a partir dos discursos da mulher agredida e de seu parceiro. Saúde soc., São Paulo, v. 18, n. 2, Junho 2009. Disponível em: $<$ http://www.scielo.br/scielo.php?script=sci_arttext\&pid=S0104-

12902009000200008\&lng=en\&nrm=iso >. Acesso em: 10 out. 2013.

EKMAN, P. A linguagem das emoções: Revolucione sua comunicação e seus relacionamentos reconhecendo todas as expressões das pessoas ao redor. São Paulo: Lua de Papel, 2011.

FARIA, J. B. de; SEIDL, E. M. F. Religiosidade e enfrentamento religioso em contextos de saúde e doença: Revisão da literatura. Psicologia: Reflexão e Crítica, 2005, 18 (3), p. 381-389. Disponível em: http://www.google.com.br/url?sa=t\&rct=j\&q=\&esrc=s\&source=web\&cd=1\&ved=0CD AQFjAA\&url=http\%3A\%2F\%2Fwww.scielo.br\%2Fpdf\%2Fprc\%2Fv18n3\%2Fa12v18 n3.pdf\&ei=WbJtUoeNGrCp7AbuqYAo\&usg=AFQjCNFPSRytKX2mMv7DmgWg5Gs S8oIAKA. Acesso em: 20 out. 2013.

FERNANDES, E. de O. J. Violência doméstica. Araçuaí: Universidade Federal de Ouro Preto - Especialização em Gestão Pública e Políticas Públicas, 2012. Disponível em:

http://www.google.com.br/url?sa=t\&rct=j\&q=\&esrc=s\&source=web\&cd=1\&ved=0CC 0QFjAA\&url=http $\% 3 \mathrm{~A} \% 2 \mathrm{~F} \% 2 \mathrm{Fwww}$.amde.ufop.br\%2Ftccs $\% 2 \mathrm{FAracuai} \% 2 \mathrm{FAracuai}$ $\% 2520-$

\%2520Eliene\%2520Fernandes.pdf\&ei=nsNtUuyPMMiqhAewv4DABA\&usg=AFQjCN Fl1GAtfjxQqqrnpSgAO2LbGPSnLw. Acesso em: 13 out.2013.

FONSECA, P. M.; LUCAS, T. N. S. Violência Doméstica contra a mulher e suas consequiências psicológicas. Fundação Bahiana para o desenvolvimento das ciências. Escola Bahiana de Medicina e Saúde Pública. Bahia, 2006. Disponível em: http://www.google.com.br/url?sa=t\&rct=j\&q=\&esrc=s\&source=web\&cd=1\&ved=0CC 0QFjAA\&url=http\%3A\%2F\%2Fnewpsi.bvs-

psi.org.br\%2Ftcc\%2F152.pdf\&ei=88NtUqWcHM6shQfG5oCADg\&usg=AFQjCNFj4eQ7cfQ7jVpFC6JGQi_bHiIHA. Acesso em: 20 mar. 2013. 
FONSECA, D. H. da; RIBEIRO, C. G.; LEAL, N. S. B. Violência doméstica contra a mulher: realidades e representações sociais. Psicol. Soc., Belo Horizonte, v. 24, n. 2, Ago. 2012. Disponível em: <http://www.scielo.br/scielo.php?script=sci_arttext\&pid=S0102$71822012000200008 \& \operatorname{lng}=$ en\&nrm=iso $>$. Acesso em: 05 out. 2013.

GADONI-COSTA, L. M.; ZUCATTI, A. P. N.; DELL'AGLIO, D. D. Violência contra a mulher: levantamento dos casos atendidos no setor de psicologia de uma delegacia para a mulher. Estud. psicol. (Campinas), Campinas, v. 28, n. 2, 2011. Disponível em: <http://www.scielo.br/scielo.php?script=sci_arttext\&pid=S0103-

166X2011000200009\&lng=en\&nrm=iso>. Acesso em: 11 Out. 2013.

GALVÃO, E. F.; ANDRADE, S. M. de. Violência contra a mulher: análise de casos atendidos em serviço de atenção à mulher em município do Sul do Brasil. Saúde e Sociedade, São Paulo, v. 3, n.2, p.89-99, mai - ago, 2004. Disponível em: http://www.scielo.br/scielo.php?pid=S0104-

12902004000200009\&script=sci_abstract\&tlng=pt. Acesso em: 15 mar. 2013.

GARBIN, C. A. S.; GARBIN, A. J. I.; DOSSI, A. P.; DOSSI, M. O. Violência doméstica: análise das lesões em mulheres. Cad. Saúde Pública, Rio de Janeiro, v. 22, n. 12, p.2567-2573, 12 dez. 2006.2 Disponível em: <http://www.scielo.br/scielo.php?script=sci_arttext\&pid=S0102-

311X2006001200007\&lng=pt\&nrm=iso >. Acesso em: 15 mar. 2013.

GOMES, N. P.; DINIZ, N. M. F.; ARAÚJO, A. J. de S.; COELHO, T. M. de F. Compreendendo a violência doméstica a partir das categorias gênero e geração. Acta Paulista de Enfermagem, São Paulo, v. 20, n.4, p. 504-508, dez. 2007. Disponível em: $\quad$ http://www.scielo.br/scielo.php?script=sci_arttext\&pid=S010321002007000400020\&lng=pt\&nrm=iso. Acesso em: 15 mar. 2013.

GUIA TRABALHISTA. Empregada em situação de violência doméstica e familiar. Disponível em: http://www.guiatrabalhista.com.br/tematicas/trabalho_mulher.htm. Acesso em: 23 out. 2013.

GUIMARÃES, L. D. O Ciúme e Suas Influências na Relação de Casais Heterossexuais em uma Perspectiva Analítica. 2012. Disponível em: http://artigos.psicologado.com/abordagens/psicologia-analitica/o-ciume-e-suasinfluencias-na-relacao-de-casais-heterossexuais-em-uma-perspectivaanalitica\#ixzz2iSC4Cbav. Acesso em: 20 out. 2013.

Instituto Maria da Penha, 2012. História. Disponível em: http://www.mariadapenha.org.br/index.php/mariadapenha/historia.html. Acesso em: 01 abr. 2013.

LEVINE, P. A. A realidade da pessoa traumatiza. In: LEVINE, P. A. O despertar do tigre. São Paulo: Summus, 1999.

LABRONICI, L. M. Processo de resiliência nas mulheres vítimas de violência doméstica: um olhar fenomenológico. Texto Contexto Enfermagem, Florianópolis, v. 21, n. 3, p. 635-632, set. 2012. Disponível em: $<$ http://www.scielo.br/scielo.php?script=sci_arttext\&pid=S010407072012000300018\&lng=pt\&nrm=iso>. Acesso: em 15 mar. 2013. MELO, Z. M. de; SILVA, D. M. da; CALDAS, M. T. Violência intrafamiliar: crimes contra a mulher na área. 2009. Metropolitana do Recife. 
NARVAZ, M. G.; KOLLER, S. H. Famílias e patriarcado: da prescrição normativa à subversão criativa. Psicologia Social, Porto Alegre, v. 18, n. 1, Abr. 2006. Disponível em: $\quad<$ http://www.scielo.br/scielo.php?script=sci_arttext\&pid=S010271822006000100007\&lng=en\&nrm=iso>. Acesso em: 05 abr. 2014.

NARVAZ, M. G.; KOLLER, S. H. Mulheres vítimas de violência doméstica: compreendendo subjetividades assujeitadas. Psicologia Social, v. 37, n. 1, Jan/Abr. 2006.

http://revistaseletronicas.pucrs.br/ojs/index.php/revistapsico/article/download/1405/110 5. Acesso em: 06 Out. 2013.

PORTO, J. R. R. Violência contra a mulher: expectativas de um acolhimento humanizado. Porto Alegre: Universidade Federal do Rio Grande do Sul, 2004. Disponível em: http://www.lume.ufrgs.br/handle/10183/4784. Acesso em: 05 out. 2013. RANGEL, C. M. F. R. B. de A.; OLIVEIRA, E. L. de. Violência contra as mulheres: fatores precipitantes e perfil de vítimas e agressores. Fazendo Gênero 9 - Diásporas, Diversidades, Deslocamentos, 2010. Disponível em: http://www.google.com.br/url?sa=t\&rct=j\&q=\&esrc=s\&source=web\&cd=1\&ved=0CC 0QFjAA\&url=http\%3A\%2F\%2Fwww.fazendogenero.ufsc.br\%2F9\%2Fresources $\% 2 \mathrm{Fa}$ nais\%2F1277848018_ARQUIVO_fazendogenero_Celina_Elzira.pdf\&ei=NrptUsbbCeif 7Aai0YHAAQ\&usg=AFQjCNEpBzU5DrO-0EKLBsxNsvdHv6XalQ. Acesso em: 04 out. 2013.

SANTI, L. N. de; NAKANO, A. M. S.; LETTIERE, A. Percepção de mulheres em situação de violência sobre o suporte e apoio recebido em seu contexto social. Texto Contexto - Enfermagem, Florianópolis, v. 19, n. 3, Set. 2010. Disponível em: $<$ http://www.scielo.br/scielo.php?script=sci_arttext\&pid=S0104-

07072010000300002\&lng=en\&nrm=iso>. Acesso em: 06 Out. 2013.

SILVA, M. V. Violência contra a mulher: quem mete a colher? In: SILVA, M. V. Violência contra a mulher: quem mete a colher? São Paulo: Cortez, 1992, p. 52 - 104. SILVA, L. L. da; COELHO, E. B. S.; CAPONI, S. N. C. de. Violência silenciosa: violência psicológica como condição da violência física doméstica. Interface (Botucatu), Botucatu, v. 11, n. 21, Abr. 2007. Disponível em: <http://www.scielo.br/scielo.php?script=sci_arttext\&pid=S1414-

32832007000100009\&lng=en\&nrm=iso>. Acesso em: 20 out. 2013.

SILVA, R. de A.; ARAÚJO, T. V. B. de; VALONGUEIRO S.; LUDERMIR, A. B. Enfrentamento da violência infligida pelo parceiro íntimo por mulheres em área urbana da região Nordeste do Brasil. Revista Saúde Pública, São Paulo, v. 46, n. 6, Dec. 2012. Disponível em: <http://www.scielo.br/scielo.php?script=sci_arttext\&pid=S0034-

89102012000600011\&lng=en\&nrm=iso>. Acesso em: 20 out. 2013.

SIMIAO, Daniel Schroeter. Representando corpo e violência: a invenção da "violência doméstica" em Timor-Leste. Revista Brasileira de Ciências Sociais, São Paulo, v. 21, n. $2006 . \quad$ Disponível em: <http://www.scielo.br/scielo.php?script=sci_arttext\&pid=S010269092006000200007\&lng=en\&nrm=iso>. Acesso em: 23 Out. 2013.

SIQUEIRA, M. J. T. Sobre o trabalho das mulheres: contribuições segundo uma analítica de gênero. Revista Rpot. v. 2, n. 1, jan - jun. 2002. Disponível em: 
http://www.periodicos.ufsc.br/index.php/rpot/article/view/6829. Acesso em: 17 mai. 2013.

SOUZA, F. B. C. de; DREZETT, J; MEIRELLES, A. de C.; RAMOS, D. G. Aspectos psicológicos de mulheres que sofrem violência sexual. RECLI. 2012; 27:98-103 Vol. 27 Núm.03 DOI: 10.1016/j.recli.2013.03.002. Disponível em: http://recli.elsevier.es/pt/aspectos-psicologicos-mulheres-que-

sofrem/articulo/90220071/. Acesso em: 20 out. 2013.

STREY, M. N. Gênero. In: JACQUES, M. da G. C. et al. Psicologia social contemporânea. Petrópolis: Vozes, 1998, p. 181- 196.

VIANNA, L. A. C.; BOMFIM, G. F. T.; CHICONE, G. Auto-estima de mulheres que sofreram violência. Revista Latino-Americana de Enfermagem, Ribeirão Preto , v. 14, n. 5, Out. 2006. Disponível em: <http://www.scielo.br/scielo.php?script=sci_arttext\&pid=S0104-

11692006000500009\&lng=en\&nrm=iso >. Acesso em: 20 out. 2013.

VIEIRA, E. M.; PERDONA, G. de C. S.; ALMEIDA, A. M. de; NAKANO, A. M. S.; SANTOS, M. A. dos; DALTOSO, D.; FERRANTE, F. G. de. Conhecimento e atitudes dos profissionais de saúde em relação à violência de gênero. Revista Brasileira de Epidemiologia, São Paulo, 2009. Disponível em: http://www.producao.usp.br/handle/BDPI/7737. Acesso em: 06 Out. 2013. 